\title{
Addendum
}

\author{
Session 3
}

\section{Integrated Crop-Livestock-Forest Systems in the Amazon: Demands of Environmental, Social and Economic Development}

\author{
Paulo Campos Christo Fernandes
}

EMBRAPA EASTER AMAZON, Belém, Brazil

Email : pauloccf@cpatu.embrapa.br

Past public policies and a lack of land regularization has contributed to deforestation in the Amazon region. The land was used for pastures after removal of hardwood and charcoal production. The disordered advance of cattle ranching in Amazonia contributed to the depletion of pasture, soil degradation, low profitability and the recent trade embargo for beef export from the State of Pará - Brazil.

The biggest challenge for sustainable territorial development of the Amazon is to change the traditional models of extensive land use. The Integrated Crop-Livestock-Forest (iLPF) can renew degraded areas through more rational use of soil.

The iLPF system retrieves degraded pastures by associating livestock with agricultural crops and forestry within the same area, simultaneously or alternatively. The technology diffused by Embrapa reduces the environmental impact from conventional ruminant production and increases local food production and renewable energy from wood of sustainable source.

Production systems in northern Brazil are diverse and complex, each situation requires a unique solution and iLPF can be adjusted to all of them. Currently, there are major producers of beef cattle as well as small dairy cattle producers using the iLPF system whereas the dairy producers use it to recover pastures and produce feedstuff for cows.

The research in the network is implemented in all northern states of Brazil. The aim is to implement and monitor iLPF systems for long-term use in public and private areas. The follow-up protocol is standardized in the search network and systems designed to compare the productive, economic and environmental aspects.

The producers' decision to adopt the system for their productions will be facilitated by the disclosure of technical indices, events and monitoring technology in the Reference Units monitored by Embrapa.

The project is funded by public and private institutions such as Embrapa, FINEP, Banco da Amazonia and Bunge and works in partnership with Sebrae. 